\title{
Leukocytoclastic Vasculitis after Steroid Injection
}

\author{
Benjamin S. Thomas
}

Key words: leukocytoclastic vasculitis, steroid

(Intern Med 51: 2491, 2012)

(DOI: 10.2169/internalmedicine.51.8238)

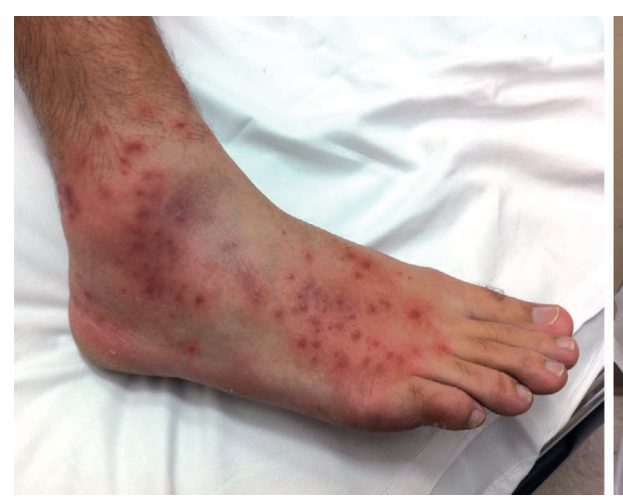

Picture 1.

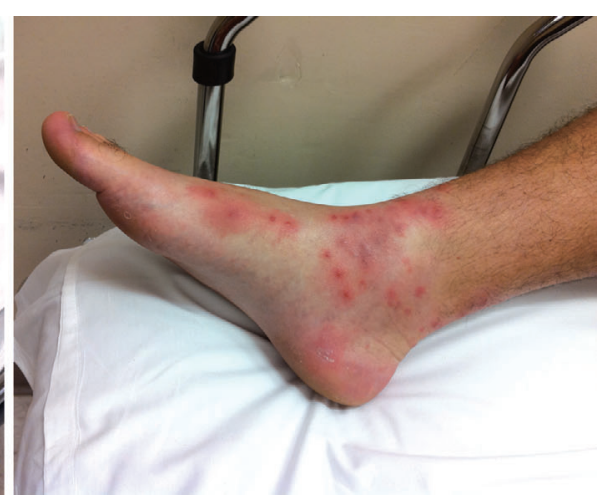

Picture 2.
A 27-year-old previously healthy male presented with an acute onset right foot pain associated with a rash. Ten days prior to admission, he underwent a steroid injection for a neuroma located between the third and fourth toes of his right foot. An examination revealed numerous erythematous non-blanchable monomorphic papules and pustules on the right dorsal foot, which had developed over the preceding 24 hours. The results of laboratory studies were within normal limits. Initial broad-spectrum antibiotics were stopped, and acyclovir at $10 \mathrm{mg} / \mathrm{kg}$ IV every 8 hours was started while awaiting the results of a skin biopsy. The pathology was consistent with leukocytoclastic vasculitis (LCV) without any viral cytopathic effects being identified. The rash resolved after the patient received a prednisone taper over a two week period. LCV is a small-vessel vasculitis that has been shown to be induced by various drugs. While the exact mechanism underlying its development is unknown, LCV may represent an immune complex mediated process, where drugs may act as haptens to generate an immune response (Picture 1, 2).

The author states that he has no Conflict of Interest (COI).

\section{References}

1. Calabrese LH, Duna GF. Drug-induced vasculitis. Curr Opin Rheumatol 8: 34-40, 1996.

2. Martinez-Taboada VM, Blanco R, Garcia-Fuentes M, RodriguezValverde V. Clinical features and outcome of 95 patients with hypersensitivity vasculitis. Am J Med 102: 186-191, 1997.

Department of Medicine, John A. Burns School of Medicine, University of Hawaii, USA

Received for publication May 29, 2012; Accepted for publication May 31, 2012

Correspondence to Dr. Benjamin S. Thomas, bsthomas@hawaii.edu

(C) 2012 The Japanese Society of Internal Medicine Journal Website: http://www.naika.or.jp/imonline/index.html 